\title{
Lacking Skills to Improve Self-Control: Reward- Induced Loss of Inhibitory Control and Overeating in Restrained Eaters
}

Citation for published version (APA):

Houben, K. M. P. I., \& Jansen, A. (2014). Lacking Skills to Improve Self-Control: Reward-Induced Loss of Inhibitory Control and Overeating in Restrained Eaters. Journal of Experimental Psychopathology, 5(1), 29-37. https://doi.org/10.5127/jep.033412

Document status and date:

Published: 01/01/2014

DOI:

10.5127/jep.033412

Document Version:

Publisher's PDF, also known as Version of record

\section{Document license:}

Taverne

Please check the document version of this publication:

- A submitted manuscript is the version of the article upon submission and before peer-review. There can be important differences between the submitted version and the official published version of record.

People interested in the research are advised to contact the author for the final version of the publication, or visit the DOI to the publisher's website.

- The final author version and the galley proof are versions of the publication after peer review.

- The final published version features the final layout of the paper including the volume, issue and page numbers.

Link to publication

\footnotetext{
General rights rights.

- You may freely distribute the URL identifying the publication in the public portal. please follow below link for the End User Agreement:

www.umlib.nl/taverne-license

Take down policy

If you believe that this document breaches copyright please contact us at:

repository@maastrichtuniversity.nl

providing details and we will investigate your claim.
}

Copyright and moral rights for the publications made accessible in the public portal are retained by the authors and/or other copyright owners and it is a condition of accessing publications that users recognise and abide by the legal requirements associated with these

- Users may download and print one copy of any publication from the public portal for the purpose of private study or research.

- You may not further distribute the material or use it for any profit-making activity or commercial gain

If the publication is distributed under the terms of Article $25 \mathrm{fa}$ of the Dutch Copyright Act, indicated by the "Taverne" license above, 


\title{
Lacking Skills to Improve Self-Control: Reward-Induced Loss of Inhibitory Control and Overeating in Restrained
}

\section{Eaters}

\author{
Katrijn Houben \& Anita Jansen \\ Maastricht University
}

\begin{abstract}
Given the vital role of inhibitory control in successful weight management, the aim of this study was to examine whether inhibitory control can be increased via incentives. Specifically, participants were randomly assigned to two conditions: In the reward condition, participants could earn a monetary bonus by performing well during an inhibition task. In the control condition, participants were not rewarded for their inhibition performance. Afterwards, we measured participants' craving and food intake during a taste test. Further, dietary restraint was included as a potential moderating factor: Restrained eaters chronically attempt to limit their food intake but are generally unsuccessful in their dieting attempts, due to decreased inhibitory control abilities. Results showed that, compared to the control condition, unrestrained eaters in the reward condition significantly improved in inhibitory control, experienced less craving for food, and also consumed less calories during the taste test. Restrained eaters, in contrast, were unable to improve inhibition performance, reported higher craving for food, and consumed more calories during the taste test relative to control. Restrained eaters therefore appear incapable of applying effective inhibition strategies and would probably benefit more from extensive training procedures that gradually increase inhibitory control in order to facilitate successful weight control.
\end{abstract}

(c) Copyright 2013 Textrum Ltd. All rights reserved.

Keywords: Dietary restraint; Inhibitory control; Reward; Stop-Signal Task

Correspondence to: Katrijn Houben, Clinical Psychological Science, Maastricht University, PO BOX 616, 6200 MD Maastricht, The Netherlands. Email: K.Houben@maastrichtuniversity.nI

Received 27-Nov-2012; received in revised form 22-May-2013; accepted 21-Jun-2013 


\title{
Table of Contents
}

\author{
Introduction \\ Material and Methods \\ Participants \\ Materials and Measures \\ Stop-Signal Task (SST) \\ Restraint Scale. \\ Taste Test. \\ Craving for Food. \\ Procedure \\ Results \\ Inhibitory Control \\ Craving and Consumption \\ Discussion \\ References
}

\section{Introduction}

As the prevalence of overweight and obesity continues to rise (e.g. Bessesen, 2008), more and more people resort to dieting strategies to attain a healthy weight (e.g. Bish, Blanck, Serdula, Kohl, \& Khan, 2004; Kruger, Galuska, Serdula, \& Jones, 2004; Weiss, Galuska, Khan, \& Serdula, 2006). Reducing one's body weight and maintaining this lower body weight over an extended period of time, however, remains difficult for most people (e.g. Jeffery et al., 2000; Mann et al., 2007; Wing \& Phelan, 2005). Thus, while for some people maintaining a healthy weight is fairly easy, weight regulation appears extremely difficult for others. This is especially true for the so-called restrained eaters, who are constantly concerned with their weight and want to restrict caloric intake (Herman \& Polivy, 1980). Despite the chronic desire to restrict their food intake, restrained eaters are mostly unsuccessful in their dieting attempts (Herman \& Polivy, 1980) and are more prone to overeating than unrestrained eaters (Jansen \& Van den Hout, 1991; Rogers \& Hill, 1989).

Although multiple factors contribute to overweight and obesity, one factor that seems to play a vital role in weight regulation is impulsivity (Nederkoorn, Havermans, Roefs, Smulders, \& Jansen, 2006). Impulsivity can be generally defined as the tendency to think, control and plan insufficiently and relies heavily on the capacity for response inhibition (Logan, Schachar, \& Tannock, 1997; Miyake, Friedman, Emerson, Witzki, \& Howerter, 2000). When defined as an insufficient response inhibition, impulsivity can be seen as the inability to overrule impulsive, habitual reactions, thereby disabling goal-oriented actions. As such, inefficient response inhibition may increase the vulnerability to the temptations of tasty high caloric food, and consequently to overconsumption, overweight, and unsuccessful weight regulation. Consistent with this idea, research showed that people with less effective response inhibition eat more high calorie food (Guerrieri et al., 2007), are more often overweight or obese (Guerrieri, Nederkoorn, \& Jansen, 2008; Nederkoorn, Braet, Van Eijs, Tanghe, \& Jansen, 2006; Nederkoorn, Guerrieri, Havermans, Roefs, \& Jansen, 2009), and lose less weight during weight reduction treatment (Nederkoorn, Jansen, Mulkens, \& Jansen, 2007) than people with effective inhibitory control. Further, restrained eaters, who are generally unsuccessful in their dieting attempts, also have more difficulty inhibiting prepotent responses, compared to controls (Jansen et al., 2009; Nederkoorn, Van Eijs, \& Jansen, 2004).

Considering the crucial role of inhibitory control in weight regulation, it would be worthwhile to study new strategies to improve inhibition. Dieting will be easier and probably more successful when inhibitory control is increased. Therefore, this kind of research is extremely useful for the development of interventions for people who are unsuccessful in their dieting attempts like restrained eaters. However, strengthening inhibitory control has been found to be difficult, at least more difficult compared to (temporarily) decreasing inhibition (or increasing impulsive responding; Guerrieri, Nederkoorn \& Jansen, 2012). Thus, the challenge is to find ways that promote an increase in inhibition. 
In this study it was examined whether inhibitory control can be increased via positive reinforcement in both restrained and unrestrained eaters. Since positive reinforcement typically strengthens the reinforced behaviour (e.g. frequency, duration, magnitude, and latency of the behaviour; Skinner, 1953), it should be possible to also increase inhibitory control by reinforcing inhibition performance. In addition, we also examined whether positive reinforcement of inhibitory control would influence eating behaviour. Specifically, participants were told they could earn a monetary bonus (i.e., positive reinforcer) by performing well during an inhibition task. Participants in the control condition, in contrast, were not rewarded for their inhibition performance. Afterwards, we measured participants' craving and food intake during a taste test of palatable, high calorie food. It was expected that rewarding performance would increase inhibition, and subsequently decrease craving and food consumption. Because especially restrained eaters have difficulty in regulating their consumption behaviour, it was examined whether the inhibition manipulation was equally effective for restrained vs. unrestrained eaters.

\section{Material and Methods}

\section{Participants}

Thirty-five female participants (age: $M=20.97, S D=2.22$; Body Mass Index $\left(B M I: \mathrm{kg} / \mathrm{m}^{2}\right.$ ): $M=22.90, S D=2.86$; range 18.42-33.30) completed the study in return for a gift certificate. Current dieters were excluded from the study. Dietary restraint $(M=12.60, S D=4.38$; range 4-23) was measured using the revised Restraint Scale (Herman \& Polivy, 1980). Participants were randomly assigned to one of two conditions: Reward $(n=16)$ or control $(n=19)$. The two conditions did not differ significantly in age $(F<1)$, BMI $(F<1)$, or restraint $(F=1.1)$.

\section{Materials and Measures}

\section{Stop-Signal Task (SST)}

The SST (Logan et al., 1997) involves two concurrent tasks: A go task, which is a choice reaction time task, and a stop task, occurring on $25 \%$ of the trials, which involves a stop signal that requires participants to inhibit their responses to the go task. During the SST, the letter $O$ or the letter $X$ was presented for $1000 \mathrm{~ms}$, preceded by a $500 \mathrm{~ms}$ fixation point. During go trials, participants had to respond as fast as possible to the $X$ and the $O$ using a left and a right response key on the keyboard (e.g. press left for $X$ and press right for $O$; instructions were counterbalanced across participants). On $25 \%$ of the trails, an auditory stop signal was presented (through headphones) and participants were instructed not to respond when this stop signal was presented. Initially, the delay between the go signal ( $\mathrm{X}$ or $\mathrm{O}$ ) and the stop signal was set at $250 \mathrm{~ms}$. Depending on the performance of the participants, a tracking procedure adapted the go-stop delay dynamically: If participants succeeded in inhibiting their response, the go-stop delay was increased by $50 \mathrm{~ms}$, thereby making it more difficult to inhibit during the next stop trial. If participants failed to inhibit their response, the go-stop delay was decreased by $50 \mathrm{~ms}$, thereby making it easier to inhibit during the next stop trial. The SST was designed to enable participants to correctly inhibit $50 \%$ of the stop trials. The SST consisted of two practice blocks without stop signals, one practice block with stop signals, and two test blocks of 64 trials.

Participants were randomly assigned to either the reward condition or the control condition. In the control condition, no extra instructions for performing the SST were given. Participants in the reward condition, in contrast, were instructed that they would be able to earn credits for correct performance during the SST. They were also informed that they would receive a monetary bonus at the end of the experiment depending on the number of credits earned during the task. They were encouraged to try to collect as many credits as possible, but were not informed about the size of the bonus. To ensure that participants would give equal importance to both the go task and the stop task, participants were rewarded 1 credit for accurate and fast (i.e., participants were too slow when their RT was higher than $2 S D$ above the mean RT in the practice block) performance on go trials, and 3 credits for correctly stopping during stop trials. In this way, participants could earn the same amount of credits for go trials ( $75 \%$ of the trials) as for stop trials ( $25 \%$ of the trials). 
The assumption underlying the SST is that response inhibition succeeds or fails depending on the relative finishing time of two parallel processes that race against each other: a go process triggered by the go signal, and a stop process triggered by the stop signal. If the stop process finishes before the go process, subjects inhibit their response. However, if the go process finishes before the stop process, subjects fail to inhibit their response. The tracking procedure is designed to find a stop-signal delay at which point the go process and the stop process on average finish at the same time. The two variables of interest are: (1) the go signal reaction time, and (2) the stopsignal delay, which represents the starting point of the stop process. From these two variables, it is possible to estimate the covert latency of the stop process, the stop signal reaction time (SSRT), by subtracting the stop delay from go RT. SSRT thus reflects the time required for successful inhibition of the go response, and therefore higher SSRTs indicate decreased inhibitory control. In the analyses, we only used SSRT during the final test block, because we did not expect participants in the reward condition to be able to improve their performance on the SST immediately.

\section{Restraint Scale.}

The revised Restraint Scale (RS; Herman \& Polivy, 1980) consists of 10 items and assesses frequency of dieting, attitudes toward eating, and weight fluctuations. Individuals scoring 15 or more are classified as restrained eaters; those scoring 14 or less are classified as unrestrained eaters.

\section{Taste Test.}

During the taste test, participants were asked to taste and rate two types of paprika-flavored crisps (542.5 Kcal/100 gr) that were placed in front of them in large bowls. Participants were instructed to consume as much or as little as they wished to judge the taste of the food products. They rank ordered and evaluated the two types of food on several dimensions, including palatability of the food, smell, and texture. The experimenter left the test room during the taste test and returned after 10 minutes and removed the bowls of food. Importantly, the primary interest was not how participants rated the types of food, but rather how much they consumed of each type of food. Without the participants' knowledge, the experimenter weighed the bowls of food before and after the taste test outside the test room. Energy intake was calculated by multiplying weight consumed of each food product by its caloric density.

\section{Craving for Food.}

Participants rated how much they craved to eat something at that specific moment on a $100 \mathrm{~mm}$ Visual Analogue Scale (VAS; no craving at all - a lot of craving).

\section{Procedure}

Participants were asked to not eat anything for 2 hours before the start of the study. After giving consent, participants performed the SST. Next, participants rated their craving for food and they performed the taste test. Finally, participants filled out the Restraint Scale (RS), and weight and length were measured to calculate BMI. At the end of the study, all participants were thanked for their cooperation and received course credit or a gift certificate of $5 €$ as remuneration for their participation. Participants in the reward condition, in addition, also received the bonus based on their performance during the SST (the max. bonus was $7.5 €$ ).

\section{Results}

\section{Inhibitory Control}

First, we examined the effect of reward and dietary restraint on inhibitory control (SSRT) using ANCOVA with condition (reward versus control) as a between-subjects factor and restraint as a continuous covariate. While the main effect of condition, $F(1,31)=.07, p=.80$, and restraint, $F(1,31)=2.97, p=.10$, were not significant, the interaction between condition and restraint was significant, $F(1,31)=9.34, p<.01$. To further examine this interaction, we next analyzed the effect of condition separately for participants scoring high or low on the restraint scale (respectively 1 SD above and 1 SD below the mean restraint score; see Cohen, Cohen, West, \& Aiken, 2003, 
for this procedure). As shown in Figure 1, restrained eaters in the reward condition performed significantly worse on the SST compared to the control condition, $F(1,31)=7.86, p<.01$. Unrestrained eaters, in contrast, showed increased inhibitory control on the SST in the reward condition compared to the control condition, $F(1,31)=4.40, p$ $=.04$. Thus, relative to control, rewarding performance on the SST significantly improved inhibitory control in unrestrained eaters, but decreased inhibitory control among restrained eaters.

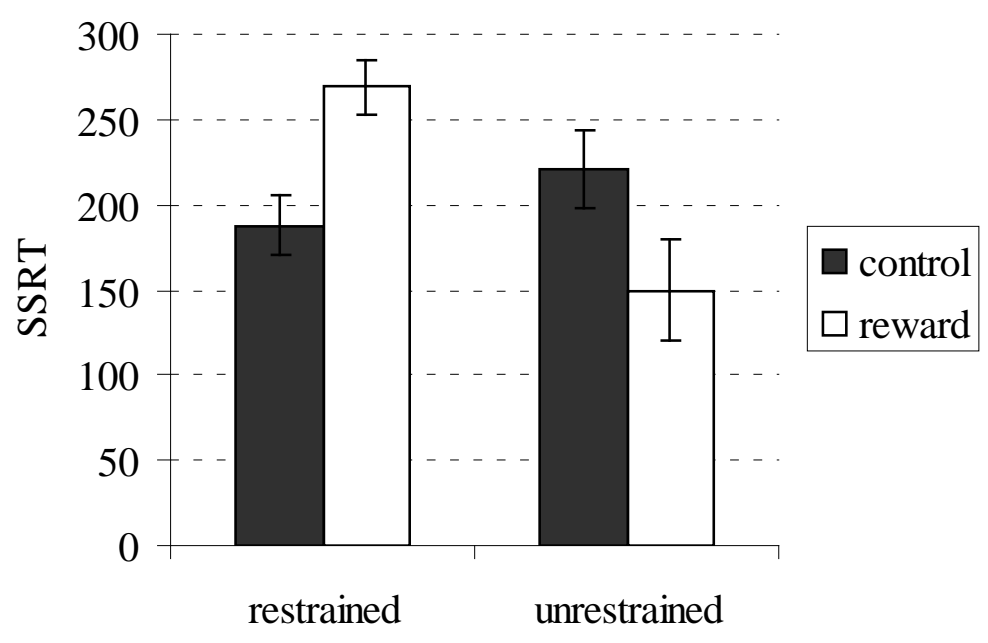

Figure 1: Estimated marginal means (with standard errors) for inhibitory control (SSRT) in the reward condition versus control condition. Means are shown separately for restrained versus unrestrained eaters (respectively 1 SD above or below the mean restraint score). Higher SSRT scores indicate decreased inhibitory control.

To further examine this finding, we also examined the effects of condition and restraint on RT during go trials as well as on the stop delay during stop trials in two separate ANCOVAs. Condition (reward versus control) was again entered as a between-subjects factor while dietary restraint was added as a continuous covariate to the model. With respect to RT, results showed no significant effect of condition, $F(1,31)=1.10, p=.30$, restraint, $F(1,31)=$ $.00, p=.97$, or interaction effect, $F(1,31)=.91, p=.35$. Follow-up analyses confirmed that there was no significant difference in go RT between the reward condition and the control condition in unrestrained eaters, $F(1,31)=.01, p$ $=.92$. However, as shown in Table 1, restrained eaters in the reward condition did show elevated go RT relative to restrained eaters in the control condition (see Table 1), although this difference was also not significant, $F(1,31)=$ 2.32, $p=.14$. With respect to stop delay, showed no significant effect of condition, $F(1,31)=1.38, p=.25$, restraint, $F(1,31)=2.36, p=.14$, or interaction effect, $F(1,31)=2.34, p=.14$. Follow-up analyses showed no significant difference in stop delay between the reward and control condition in restrained eaters, $F(1,31)=.29, p=$ .60. For unrestrained eaters, however, results showed a marginally significant effect suggesting higher stop delays in the reward condition compared to the control condition, $F(1,31)=3.21, p=.08$ (see Table 1).

\section{Craving and Consumption}

The correlation between craving and food consumption during the taste test was not significant, $r=.18, p=.30$, but was significant after excluding two influential outlier (Cook's distance $>4 / \mathrm{n}$ ), $r=.47, p=.01$. The effect of reward and restraint on craving as well as food consumption during the taste test was examined using ANCOVA with condition (reward versus control) as a between-subjects factor and restraint as a continuous covariate. With respect to craving, results showed no main effect of condition, $F(1,31)=.11, p=.74$. The main effect of restraint was significant, $F(1,31)=4.91, p=.03$, indicating increased craving in restrained compared to unrestrained eaters. This main effect, however, was qualified by a significant two-way interaction between restraint and condition, $F(1$, $31)=8.53, p<.01$. Follow-up analyses therefore examined the effect of condition separately for high (+ $1 S D)$ versus low restrained eaters $(-1 S D)$. As illustrated in Figure 2, craving was higher among restrained eaters in the reward condition compared to restrained eaters in the control condition, $F(1,31)=5.24, p=.03$. In unrestrained 
eaters, in contrast, craving was significantly lower in the reward condition than in the control condition, $F(1,31)=$ $5.46, p=.03$.

Table 1

\begin{tabular}{|c|c|c|c|c|c|c|}
\hline & \multicolumn{2}{|c|}{ Go RT } & \multicolumn{2}{|c|}{ Stop delay } & \multicolumn{2}{|c|}{ SSRT } \\
\hline & $M$ & $S E$ & $M$ & $S E$ & $M$ & $S E$ \\
\hline \multicolumn{7}{|l|}{ Restrained } \\
\hline Reward & 474.32 & 33.38 & 205.34 & 24.81 & 268.98 & 22.85 \\
\hline Control & 410.01 & 25.90 & 222.12 & 19.25 & 187.89 & 17.72 \\
\hline \multicolumn{7}{|l|}{ Unrestrained } \\
\hline Reward & 438.23 & 44.05 & 288.24 & 32.74 & 150.00 & 30.15 \\
\hline Control & 443.34 & 22.68 & 222.27 & 16.85 & 221.07 & 15.52 \\
\hline
\end{tabular}

Note: Estimated marginal means (with standard errors) for RT during go trials (go RT), stop delay during stop trials, and StopSignal Reaction Time (SSRT; computed as mean go RT - mean stop delay). Higher SSRT scores indicate decreased inhibitory control. Estimated means are shown separately for restrained versus unrestrained eaters (respectively $1 S D$ above or below the mean restraint score) and separately for the reward and control conditions.

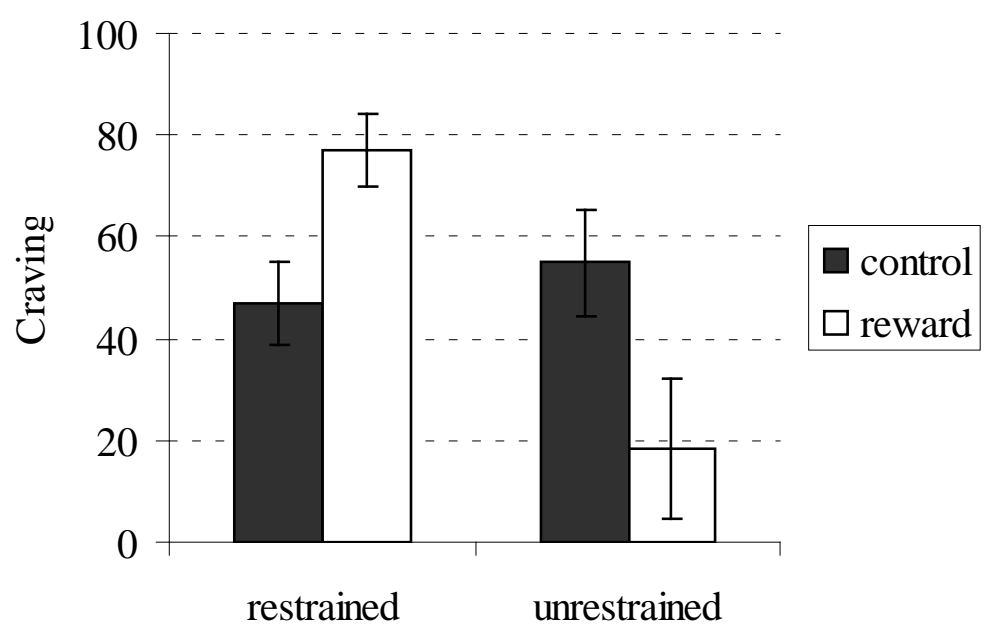

Figure 2: Estimated marginal means (with standard errors) for craving in the reward condition versus control condition. Means are shown separately for restrained versus unrestrained eaters (respectively 1 SD above or below the mean restraint score).

Similarly, the analysis on food intake revealed no significant main effects of condition, $F(1,31)=.22, p=.64$, or restraint, $F(1,31)=3.26, p=.08$, while the interaction between restraint and condition was significant, $F(1,31)=$ $7.96, p<.01$. Follow-up analyses showed that food intake was significantly higher in restrained eaters in the reward condition compared to restrained eaters in the control condition, $F(1,31)=7.53, p=.01$. In contrast, unrestrained eaters in the reward condition consumed less than unrestrained eaters in the control condition, although this effect was only marginally significant, $F(1,31)=3.25, p=.08$ (see Figure 3 ). Thus, relative to control, rewarding fast and accurate performance on the SST not only increased inhibitory control in unrestrained eaters, but also decreased craving and food intake. In restrained eaters, in contrast, rewarding SST performance had the opposite effect with decreased inhibitory control and increased craving and food intake compared to controls. 


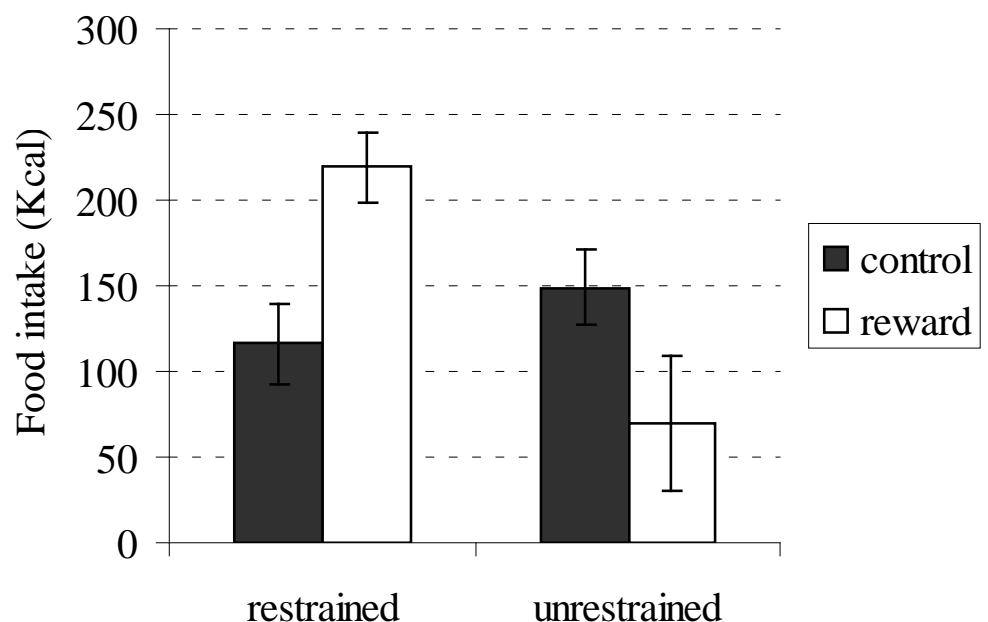

Figure 3: Estimated marginal means (with standard errors) for food intake in the reward condition versus control condition. Means are shown separately for restrained versus unrestrained eaters (respectively 1 SD above or below the mean restraint score).

\section{Discussion}

Success at achieving and maintaining a healthy body weight critically depends upon the ability to inhibit impulsive responding to palatable food. Especially restrained eaters, who are preoccupied with restricting their food intake, have been shown to lack inhibitory control skills needed for weight regulation compared to normal, unrestrained eaters. Therefore, the aim of the present research was to examine whether both restrained and unrestrained eaters can increase inhibitory control abilities and decrease food consumption in response to an incentive to perform well on an inhibition task. More precisely, participants were randomly assigned to two conditions: In the reward condition, participants were offered a monetary incentive based on fast responding and inhibitory performance. In the control condition, in contrast, participants were not given the opportunity to earn a monetary bonus for their performance. Among unrestrained eaters, offering an incentive to perform well indeed resulted in increased inhibitory control. More importantly, unrestrained eaters who were rewarded for inhibition performance showed less craving for food, and also consumed less high calorie food during a taste test compared to control. In contrast, restrained eaters were incapable of increasing their inhibition performance when offered an incentive and even performed worse during the inhibition task compared to control. Moreover, restrained eaters in the reward condition did not only show decreased inhibitory control relative to control, but also increased craving for food and consumed more high calorie food.

The present findings thus show that giving an incentive for increasing inhibitory control performance effectively improves inhibition performance in unrestrained eaters, but not in restrained eaters. Importantly, when RT and stop delays were analyzed separately, it also became evident that this was not due to restrained eaters being unresponsive to performance incentives. While unrestrained eaters seem to be able to improve (i.e., shorten) their stopping process (thereby decreasing SSRT), restrained eaters instead seem to rely on an ineffective strategy to increase their inhibition performance and are incapable of effectively decreasing the stopping process. Specifically, unrestrained eaters seemed able to improve their stopping performance during the inhibition task, while restrained eaters attempted to improve their performance by reacting more slowly. However, they were not able to improve their stopping performance (i.e. to inhibit responses during stop trials) as their stop delay remained unaffected. Hence, these findings demonstrate that unrestrained eaters are able to improve their inhibition performance directly without reacting more slowly when motivated to do so. For restrained eaters, in contrast, increasing the motivation to exert inhibitory control appears insufficient to boost inhibition performance and causes them to rely on ineffective strategies in an attempt to improve performance (i.e., acting slower). Together these findings therefore suggest that restrained eaters do not possess the necessary skills to increase inhibitory control. 
The implication of these findings is that restrained eaters would probably benefit more from training procedures designed to practice and improve inhibitory control gradually rather than from incentive-based manipulations. Recent evidence indeed suggests that this might indeed be a promising way to promote successful weight control. For instance, consistently withholding food-related responses in training versions of inhibition tasks has been demonstrated to significantly reduce consumption of palatable, high calorie food (Houben, 2011; Houben \& Jansen, 2011). Moreover, such training was especially effective for people who already experienced difficulty controlling their food intake (Houben, 2011). Therefore, it would be interesting to examine the effectiveness of such training interventions in restrained eaters to see whether this would increase dieting success as well as the maintenance of a healthy body weight over a longer period of time.

\section{References}

Bessesen, D. H. (2008). Update on obesity. Journal of Clinical Endocrinology \& Metabolism, 93, 2027-2034. http://dx.doi.org/10.1210/jc.2008-0520

Bish, C., Blanck, H., Serdula, M., Kohl, H., \& Khan, L. (2004). Diet and physical activity behaviors among Americans trying to maintain weight. Obesity Research, 12, A206-A207.

Cohen, J., Cohen, P., West, S. G., \& Aiken, L. S. (2003). Applied multiple regression/correlation analysis for the behavioral sciences. Hillsdale, $\mathrm{NJ}$ : Erlbaum.

Guerrieri, R., Nederkoorn, C., \& Jansen, A. (2012). Disinhibition is easier learned than inhibition. The effects of (dis)inhibition training on food intake. Appetite, 59, 96-99. http://dx.doi.org/10.1016/j.appet.2012.04.006

Guerrieri, R., Nederkoorn, C., \& Jansen, A. (2008). The interaction between impulsivity and a varied food environment: its influence on food intake and overweight. International Journal of Obesity, 32, 708-714. http://dx.doi.org/10.1038/sj.ijo.0803770

Guerrieri, R., Nederkoorn, C., Stankiewicz, K., Alberts, H., Geschwind, N., Martijn, C., \& Jansen, A. (2007). The influence of trait and induced state impulsivity on food intake in normal-weight healthy women. Appetite, 49, 6673. http://dx.doi.org/10.1016/j.appet.2006.11.008

Herman, C. P., \& Polivy, J. P. (1980). Restrained eating. In A. J. Stunkard (Ed.), Obesity (pp. 208-225). Philadelphia: Saunders.

Houben, K. (2011). Overcoming the urge to splurge: The role of inhibitory control in eating behavior. Journal of Behavior Therapy and Experimental Psychiatry, 42, 384-388. http://dx.doi.org/10.1016/i.jbtep.2011.02.008

Houben, K., \& Jansen, A. (2011). Training inhibitory control: A recipe for resisting sweet temptations. Appetite, 56, 345-349. http://dx.doi.org/10.1016/j.appet.2010.12.017

Jansen, A., Nederkoorn, C., van Baak, L., Keirse, C., Guerrieri, R., \& Havermans, R. (2009). High-restrained eaters only overeat when they are also impulsive. Behaviour Research and Therapy, 47, 105-110. http://dx.doi.org/10.1016/i.brat.2008.10.016

Jansen, A., \& Van den Hout, M. (1991). On being led into temptation: 'Counterregulation' of dieters after smelling a 'preload'. Addictive Behaviors, 5, 247-253. http://dx.doi.org/10.1016/0306-4603(91)90017-C

Jeffery, R. W., Epstein, L. H., Wilson, G. T., Drewnowski, A., Stunkard, A. J., \& Wing, R. R. (2000). Long-term maintenance of weight loss: Current status. Health Psychology, 19, 5-16. http://dx.doi.org/10.1037/02786133.19.Suppl1.5

Kruger, J., Galuska, D. A., Serdula, M. K., \& Jones, D. A. (2004). Attempting to lose weight - Specific practices among US adults. American Journal of Preventive Medicine, 26, 402-406. http://dx.doi.org/10.1016/j.amepre.2004.02.001

Logan, G. D., Schachar, R. J., \& Tannock, R. (1997). Impulsivity and inhibitory control. Psychological Science, 8 , 60-64. http://dx.doi.org/10.1111/i.1467-9280.1997.tb00545.x

Mann, T., Tomiyama, A. J., Westling, E., Lew, A.-M., Samuels, B., \& Chatman, J. (2007). Medicare's search for effective obesity treatments: Diets are not the answer. American Psychologist, 62, 220-233. http://dx.doi.org/10.1037/0003-066X.62.3.220

Miyake, A., Friedman, N. P., Emerson, M. J., Witzki, A. H., \& Howerter, A. (2000). The unity and diversity of executive functions and their contributions to complex "frontal lobe" tasks: A latent variable analysis. Cognitive Psychology, 41, 49-100. http://dx.doi.org/10.1006/cogp.1999.0734 
Nederkoorn, C., Braet, C., Van Eijs, Y., Tanghe, A., \& Jansen, A. (2006). Why obese children cannot resist food: The role of impulsivity. Eating Behaviors, 7, 315-322. http://dx.doi.org/10.1016/i.eatbeh.2005.11.005

Nederkoorn, C., Guerrieri, R., Havermans, R. C., Roefs, A., \& Jansen, A. (2009). The interactive effect of hunger and impulsivity on food intake and purchase in a virtual supermarket. International Journal of Obesity and Related Metabolic Disorders, 33, 905-912. http://dx.doi.org/10.1038/ijo.2009.98

Nederkoorn, C., Havermans, H., Roefs, A., Smulders, F. T. Y., \& Jansen, A. (2006). Impulsivity in obese women. Appetite, 47, 253-256. http://dx.doi.org/10.1016/j.appet.2006.05.008

Nederkoorn, C., Jansen, E., Mulkens, S., \& Jansen, A. (2007). Impulsivity predicts treatment outcome in obese children. Behaviour Research and Therapy, 45, 1071-1075. http://dx.doi.org/10.1016/j.brat.2006.05.009

Nederkoorn, C., Van Eijs, Y., \& Jansen, A. (2004). Restrained eaters act on impulse. Personality and Individual Differences, 37, 1651-1658. http://dx.doi.org/10.1016/j.paid.2004.02.020

Rogers, P. J., \& Hill, A. J. (1989). Breakdown of dietary restraint following mere exposure to food stimuli: Interrelationship between restraint, hunger, salivation, and food intake. Addictive Behaviors, 14, 387-397. http://dx.doi.org/10.1016/0306-4603(89)90026-9

Skinner, B.F. (1953). Science and Human Behavior. New York: Macmillan.

Weiss, E. C., Galuska, D. A., Khan, L. K., \& Serdula, M. K. (2006). Weight-control practices among US adults, 2001-2002. American Journal of Preventive Medicine, 31, 18-24.

http://dx.doi.org/10.1016/j.amepre.2006.03.016

Wing, R. R., \& Phelan, S. (2005). Long-term weight loss maintenance. American Journal of Clinical Nutrition, 82, 222S-225S. 